\title{
CUIDADO DA CRIANÇA COM ANOMALIA CONGÊNITA: A EXPERIÊNCIA DA FAMÍLIAa
}

\author{
Caring for a child with congenital anomalies: the experience of the family \\ Cuidados con un niño con anomalía congénita: la experiencia de la familia
}

Bruna Aparecida Bolla

Stéphany Noujain Fulconi

Marja Rany Rigotti Baltor ${ }^{3}$

Giselle Dupas ${ }^{4}$

\section{RESUMO}

0 prognóstico de sobrevida de crianças com anomalia congênita vem apresentando melhora; deste modo, é importante conhecer a vivência da família ao aceitar e inserir essa criança na sociedade. Entretanto, os profissionais da saúde, dentre eles o enfermeiro, ainda têm dificuldades relacionadas ao acompanhamento e orientação da família. 0 objetivo deste trabalho foi conhecer a experiência da família no cuidado à criança portadora de anomalia congênita. 0 referencial teórico utilizado foi o Interacionismo Simbólico, e o método, a Narrativa. Das experiências vivenciadas, o momento do diagnóstico foi considerado um dos que causa maior sofrimento à família. Após esse período, o enfrentamento diário para a saúde e bem-estar da criança tornou-se objetivo fundamental. Concluiu-se que a assistência à família deve se basear em uma rede de apoio que a acolha principalmente no momento do diagnóstico e durante as especificidades do cuidado à criança.

Palavras-chave: Anormalidade congênita. Enfermagem. Família. Criança.

\begin{abstract}
The survival of children with congenital anomaly comes with improved prognosis, so that it is important to know the experiences of the family to accept and place the child in society. However, health professionals, including nurses, still have difficulties related to the monitoring and guidance of this family. The objective of this study was to identify the family's experience in caring children with a congenital anomaly. The theoretical framework used was Symbolic Interactionism and narrative as methodology, respectively. From the experiences reported, the time of diagnosis was considered a major cause for the family suffering. After this period, facing daily health and welfare of the child became the prime objective. So, it was concluded that the assistance the family must rely on a support network assisting the family at the diagnosis and during the particularities of child care.
\end{abstract}

Keywords: Congenital abnormality. Nursing. Family. Child.

\section{Resumen}

La sobrevida de niños con anomalía congénita viene presentando mejora en el pronóstico, siendo importante conocer la vivencia de la familia al aceptar e insertar ese niño en la sociedad. Sin embargo, los profesionales de la salud, incluyendo el enfermero, todavía tienen dificultades relacionadas al acompañamiento y orientación de esa familia. El objetivo de este estudio fue identificar la experiencia de la familia en el cuidado al niño con una anomalía congénita. El referencial teórico utilizado fue el Interaccionismo Simbólico y la Narrativa como método. De las experiencias vividas, el momento del diagnóstico fue considerado la etapa principal del sufrimiento de la familia. Después de este período, el enfrentamiento diario para la salud y el bienestar del niño se convirtió en objetivo primordial. Se concluyó que la asistencia a la familia debe contar con una red de apoyo que abarque principalmente el momento del diagnóstico y a las características de cuidado al niño.

Palabras claves: Anomalías congénitas. Enfermería. Familia. Niño

\footnotetext{
${ }^{1}$ Aluna da Graduação em Enfermagem da Universidade Federal de São Carlos. Barra Bonita - SP. Brasil. E-mail: brunabolla@uol.com.br; ${ }^{2}$ Aluna da Graduação em Enfermagem da Universidade Federal de São Carlos. Campinas -SP. Brasil. E-mail: tepy711@yahoo.com.br ;'Enfermeira. Mestre em Enfermagem. Programa de Pós-Graduação em Enfermagem da Universidade Federal de São Carlos. Membro do Grupo Saúde e Família. São Carlos - SP. Brasil. E-mail: marjabaltor@gmail.com ; ${ }^{4}$ Enfermeira. Doutora. Professora Associada. Departamento de Enfermagem da Universidade Federal de São Carlos. Líder e pesquisadora do Grupo Saúde e Família/CNPq. São Carlos - SP. Brasil. E-mail: gdupas@ufscar.br
} 


\section{INTRODUÇÃO}

Em decorrência dos avanços tecnológicos para melhoria das condições de nascimento e de assistência à saúde infantil, observa-se um aumento na sobrevida de crianças que nascem com anomalia congênita. 0 avanço da medicina também permitiu identificar patologias na gestação e realizar intervenções intrauterinas, colaborando, consequentemente, com o prognóstico fetal ${ }^{1}$.

As anomalias congênitas acarretam grande impacto à família já que a deficiência traz consigo a perda do filho idealizado. Esse processo de luto é diferente, pois a criança está viva e os pais, em um primeiro momento, não acreditam no diagnóstico, ocorrendo choque e descrença ${ }^{2}$.

Logo, a notícia da anomalia congênita causa um grande impacto no ambiente familiar e desperta sentimentos de pavor diante do desconhecido. A família apreende o momento como uma sentença de conotação negativa para a criança e para si. Os familiares se percebem frágeis e demonstram medo perante as possíveis dificuldades que irão enfrentar. Inicialmente a preocupação centra-se nos aspectos do cuidado à criança e é envolta por ansiedade quanto à sobrevivência e alimentação; posteriormente surgem preocupações com a questão estética da deformidade estrutural ${ }^{3}$.

Para superar as adversidades é fundamental que as famílias recebam apoio e informações dos profissionais envolvidos com a assistência, preferencialmente de uma equipe multidisciplinar. Não basta o tratamento clínico, é necessário conhecer formas que promovam a inserção dessa criança no meio familiar e na sociedade, bem como a prevenção da discriminação que ela pode vir a sofrer ${ }^{3}$. Nesse contexto, as propostas de intervenções de enfermagem na família ainda são deficitárias ${ }^{1}$.

Quando é ofertado suporte às famílias que enfrentam essa situação, elas apresentam menor nível de estresse, ansiedade e depressão, além de manter uma perspectiva mais positiva em relação à doença da criança e visualizar a situação de forma realista ${ }^{3}$.

A partir dessas proposições, o presente estudo teve como objetivo geral conhecer a experiência da família no cuidado da criança com anomalia congênita.

\section{METODOLOGIA}

Esta pesquisa utilizou o Interacionismo Simbólico (IS) como referencial teórico, cujos fundamentos se apoiam em três premissas: o ser humano age em relação às coisas com base nos sentidos que tais coisas têm para ele; o sentido das coisas se origina na interação social que o indivíduo estabelece com os outros; os significados são modificados por meio da interpretação pessoal ${ }^{4}$.

Como método foi utilizada a Narrativa, já que narrar é uma manifestação humana. Ao narrar a sua vivência, a família permite que captemos a sua visão de mundo, seus valores e pressupostos que utiliza para definir a sua experiência e, assim, nos possibilita uma maior compreensão da vivência ${ }^{5}$.

Assim, foram realizadas entrevistas, as quais, após transcrição sistemática, foram relidas com a finalidade de depreender a experiência da família. Também foram realizadas seleções de falas/expressões que contribuíam com a proposta do projeto. Essas falas/expressões foram selecionadas e transformadas em discursos. Esses discursos (tendo apenas as falas dos familiares em seu conteúdo) foram analisados de maneira a identificar os anseios e vivências experienciadas pela família, de acordo com sequências que nos permitissem o encontro de conexões em outros momentos das narrativas. Foram destacadas palavras e/ou expressões tratadas com maior ênfase pelos entrevistados ${ }^{5}$.

Analisando as narrativas uma a uma, interpretouse o que cada participante fazia da sua experiência em ter uma criança com anomalia congênita. Com a releitura exaustiva foi possível delinear sentimentos, vivências incomuns às famílias embora cada experiência fosse única. Por conseguinte, as narrativas foram agrupadas de acordo com a semelhança de momentos, sentimentos e/ou ações. A partir desses temas emergiram subtemas que revelavam a experiência da família ${ }^{5}$.

Todos os critérios éticos foram atendidos. 0 projeto teve aprovação no Comitê de Ética de Pesquisa em Seres Humanos da Universidade Federal de São Carlos pelo parecer $n^{0}$. 189/2011 e número do processo: 0160.0.135.000-10. 0s membros familiares participantes foram esclarecidos e assinaram o Termo de Consentimento Livre e Esclarecido.

Para a realização das entrevistas, o Centro de Especialidades do município foi contactado já que nesse estabelecimento há um ambulatório de genética destinado às famílias de crianças portadoras de anomalias congênitas. De acordo com critérios de inclusão, ou seja, estar em idade pré-escolar e apresentar alguma anomalia congênita, vinte e cinco crianças foram contactadas. A pesquisa se deu com a aceitação e participação de sete famílias, que relataram suas experiências por meio de entrevistas, as quais se iniciavam com a questão norteadora: "Como é para vocês cuidar de uma criança com anomalia congênita?" As entrevistas foram gravadas e transcritas na íntegra. Para garantir o anonimato utilizamos siglas M (mãe), A (avó) e $\mathrm{P}$ (pai) seguidas dos respectivos números das entrevistas (Quadro 1). 
Cuidado da criança com anomalia congênita

Bolla BA,Fulconi SN, Baltor MRR, Dupas G

Quadro 1 - Caracterização das famílias entrevistadas.

\begin{tabular}{|c|c|c|c|c|}
\hline Participante & $\begin{array}{c}\text { Membros } \\
\text { Participantes }\end{array}$ & $\begin{array}{l}\text { Idade da Criança } \\
\text { com Anomalia }\end{array}$ & $\begin{array}{c}\text { Sexo } \\
\text { da criança }\end{array}$ & $\begin{array}{l}\text { Doença } \\
\text { Associada }\end{array}$ \\
\hline Família 1 & Avó & 2 anos 10 meses & $\bar{M}$ & Sem diagnóstico etiológico \\
\hline Família 2 & Mãe & 5 anos & $\mathrm{F}$ & Múltiplas malformações \\
\hline Família 3 & $\begin{array}{l}\text { Mãe } \\
\text { Avó }\end{array}$ & 3 anos e 2 meses & $\bar{M}$ & $\begin{array}{c}\text { Deficiência visual e atraso } \\
\text { no desenvolvimento } \\
\text { neuropsicomotor }\end{array}$ \\
\hline Família 4 & $\begin{array}{l}\text { Mãe } \\
\text { Pai }\end{array}$ & 5 anos & $F$ & Artrogripose generalizada \\
\hline Família 5 & Mãe & 2 anos & $\mathrm{F}$ & Síndrome de Down \\
\hline Família 6 & $\begin{array}{l}\text { Mãe } \\
\text { Pai }\end{array}$ & 5 anos & $\bar{M}$ & $\begin{array}{c}\text { Deficiência visual, auditiva } \\
\text { e intelectual }\end{array}$ \\
\hline Família 7 & Mãe & $\begin{array}{c}3 \text { anos e } 11 \\
\text { meses }\end{array}$ & M & $\begin{array}{l}\text { Hidrocefalia, cardiopatia, } \\
\text { esclerocórnea }\end{array}$ \\
\hline
\end{tabular}

\section{RESULTADOS E DISCUSSÃO}

A análise dos dados segundo os parâmetros da narrativa $a^{5}$ e à luz do IS permitiu três temas: VIVENCIANDO A ANOMALIA: INCERTEZASE ACEITAÇÕES, que abarca os subtemas: Luto pelo filho idealizado; Diagnóstico e suas peculiaridades, Anomalia e sociedade; e Vibrando com os progressos; FAMÍLIA E REDE DE APOIO, com os subtemas: Apoio dos profissionais da saúde; Apoio religioso; Apoio familiar; e Apoio financeiro; MUNDO QUEENVOLVE 0 CUIDADO e seus subtemas: Sentimentos do Cuidador; Superproteção; e Momentos de lazer.

\section{Vivenciando a anomalia:incertezas e aceitações}

Osfamiliares têm dificuldade em compreender o diagnóstico quando a criança nasce com anomalia congênita. Os pais se mostram preocupados com o impacto e reação que a notícia causará aos outros membros da família. À medida que a família reflete sobre a rejeição e preconceitos que a criança pode vir a sofrer, sente-se insegura e angustiada. Diante dessa notícia cada integrante busca explicações e maneiras para enfrentar essa fase. Quanto ao crescimento e desenvolvimento da criança, a família possui muitas expectativas evibra nos momentos de demonstrações de sinais de melhora da condição de saúde, acreditando no progresso paulatino da criança. Os subtemas que contemplam estetemasão apresentados aseguir.

O processo de interação consigo mesmo, com o outro mais próximo, com a sociedade, por assim dizer, aparece o tempo todo nessa vivência. 0 impacto da situação permeia as relações atuais e as projeções futuras que a família realiza.

\section{Luto pelo filho idealizado}

Durante o período gestacional, a família cria expectativa relacionada à aparência da criança esperada. Os pais aguardame desejam uma criança perfeita e saudável. Quando o filho vem ao mundo apresentando anomalias, principalmente as que interferem na imagem corporal, a decepção e tristeza são claras, evidenciadas tanto no choro ao receber a notícia quanto na atitude de esconder a criança.
Meu marido me falou bem assim: "Nossa filha está com problema no olho, problema na boca, problema no nariz, nos braços, nas mãos, nas pernas enos pés". Então eu comecei a chorar porque eu estava esperando uma criança perfeita. (M2)

Eu não saía na rua de jeito nenhum. Eu a escondia. Eu tinha vergonha. Mas agora não. (M5)

Assim, observa-se um processo de luto, uma vez que o sonho do filho idealizado não é concretizado. Em alguns casos a família rejeita momentaneamente aquela criança, acreditando não merecer tal fardo. É comum em primeira instância não acreditar no diagnóstico, como verbalizado por algumas mães.
Quando ela nasceu foi bem difícil. Eu até cortei os meus pulsos. Eu só fiquei sabendo no dia do parto. Eu fiz quatro ultrassons na gestação e não deu. Então foi um baque. Eu entrei em estado de choque porque eu não sabia que ela ia nascer desse jeito. (M5)

A literatura aponta que o diagnóstico de anomalia congênita gera reações de negação da doença, questionamento sobre 0 merecimento de ter esse filho, rejeição quanto à condição da criança, perda do sonho do filho perfeito ${ }^{2}$. Não obstante, a família vivencia momentos de inquietude por desconhecer os cuidados especiais de que a criança irá necessitar ${ }^{6}$.

\section{Diagnóstico e as suas peculiaridades}

Compreender o diagnóstico é um processo permeado por inquietudes. A família busca as possíveis razões que possam explicar a causa da anomalia. Procuram auxílio em diferentes especialidades médicas e em genética, eaté mesmo informaç̃os de fontes informais enos saberes populares.

Falaram que quando é Down não nasce com risco na mão. Então nós [avó e a madrinha] ficávamos nos vidros falando para minha filha: "Ergue a mãozinha 
dele, olha na mãozinha dele" para nós vermos se tinha. Ai nós olhamos e tinha as marquinhas. E falei: 'Graças a Deus não é'. (A1)

Quando a familia percebe algo diferente em sua criança, mas não existem diagnóstico e reconhecimento por parte dos profissionais de que algo diferente possa estar acontecendo, ela mesma realiza movimento próprio de busca por respostas.

Ele não sentava e não firmava a cabeça. Alguma coisa a gente sabia que tinha de errado. Mas como a gente já vinhafazendo vários exames que vinham comos resultados negativos, a gente não esperava que na ressonância. [...] desse esse resultado. (A3)

Com o diagnóstico em mãos, a família questiona-se sobre as razões da anomalia. Aquelas que não tiveram o diagnóstico no período de pré-natal, ao refletirem sobre a possibilidade de o terem tido durante a gestação, não cogitavam o aborto, mas consideravam que haveria mais tempo de preparo para o enfrentamento. Por outro lado, quando há tal diagnóstico, a gestação torna-se difícil, já que prospecta o futuro a ser enfrentado.

Você está no oitavo mês e vai fazer um ultrassom para saber se é menino ou menina. Então descobre que vai nascer com problema. É um choque. Você vai criando força para levar a gravidez atéo fim. (M7)

\section{Eu acho que eu reagiria da mesma forma. Não ia pensar em tirar, jamais.(M2)}

O Interacionismo Simbólico tem seus fundamentos em três premissas: o ser humano age em relação às coisas com base nos sentidos que tais coisas têm para ele; o sentido das coisas é derivado, ou se origina da interação social que o indivíduo estabelece com os outros; esses sentidos são manipulados e modificados através de um processo interpretativo, usado pela pessoa ao lidar com as coisas e situações em que ela se encontra ${ }^{4}$

Dessa forma, os familiares interpretam o diagnóstico a partir do seu contexto sociocultural, espiritual, cogitando motivos para sua ocorrência. Esse fenômeno é esperado já que o ser humano precisa atribuir um motivo para enfrentar tal situação $0^{7}$

\section{Anomalia e sociedade}

Essa categoria retrata as situações e comentários preconceituosos que afamilia enfrenta por parte da sociedade ao sair de casa com a criança. Tal fato desperta sentimentos de tristeza e indignação ao perceber que sua criança não é aceita e étratada com preconceito e distanciamento por alguns membros da sociedade. A criança malformada chama a atenção e torna-se alvo de comentários maldosos e preconceituosos, gerando assim situação conflituosa e desconfortável. Toda essa cena é captada pela familia que sofre pela rejeição da criança, assim como pelas dificuldades no convivivo e inserção social.
0 problema é que as pessoas são ignorantes, elas começam a falar muita besteira como "Não vai conseguir fazer isso, não vai conseguir fazer aquilo." (P5)

Um casal de senhores cochichava: "Olha lá, olha lá". 0 senhor falou: "Olha, eu não gosto de ver nem sangue, imagina ver isso!" (M2)

Manifestações de estranhamento causam muito sofrimento nas famílias e refletem o medo que o ser humano tem do desconhecido ${ }^{8}$. 0 preconceito da sociedade em relação às deformidades associa-se à dificuldade que há em estabelecer uma perspectiva positiva de futuro para a criança, pois culturalmente as qualificações são atribuídas de acordo com as capacidades produtivas dapessoa?.

\section{Vibrando com os progressos}

A família da criança portadora de anomalia congênita sabe que ela tem um crescimento e desenvolvimento vagarosos se comparada a outras sem anomalia; no entanto, acredita que, mesmo com suas limitações, também se desenvolverá dentro de suas possibilidades. Com isso, há esperança e expectativa diante do desenvolvimento saudável e todas as demonstrações do progresso infantil são captadas, gerando intensa vibração familiar.

São coisas bobas para as outras pessoas, mas para a gente éuma farra, éuma alegria, édiferente [...] Quando ele aprendeu a bater palminha foi uma festa [...] Foi comemorado com bolo, com direito a tudo. Émais gostoso, é mais esperado, tudo se torna muito mais gostoso. Eu acho que as familias deveriam olhar mais o lado positivo, enão o negativo. (A3)

Os eventos que demonstram evolução no desenvolvimento da criança despertam muita expectativa diante do futuro e contribuem para um melhor enfrentamento das situaç̃es, já que se acredita na superação das dificuldades e na recuperação da criança ${ }^{10}$.

\section{Família e rede de apoio}

Oapoio proporciona segurança eforça para afamilia prosseguir com os cuidados. Quando não tem apoio, a familia transita em busca de alternativas almejando o bem-estar da criança. 0 suporte pode ser dado por profissionais da saúde, pela religião, pela própriafamilia ou atémesmo pela assistência pública e privada. As interações estabelecidas ajudam ou não o processo de sustentação dafamilia.

\section{Apoio dos profissionais da área da saúde}

A maneira como a família é amparada no momento do diagnóstico de uma doença crônica interfere na experiência de enfrentamento da enfermidade ${ }^{7}$. Constatamos que os profissionais da área da saúde que, no momento da divulgação da má notícia, agiram de forma empática, foram considerados peças-chave para o enfrentamento, o que corrobora as premissas do Interacionismo 
Simbólico, que discerne que o ser humano atribui um significado a partir das suas relações sociais4; ou seja, ser amparado por um profissional o faz depreender que a situação pode ser enfrentada e, então, é menos complicada do que parece.

Ao se relacionarem com profissionais que propiciaram suporte e esclarecimento, mães de crianças hospitalizadas se sentiram seguras para assumir o cuidado integral já que o acolhimento e a empatia desses profissionais as fortaleceram ${ }^{11}$.

Foi trazida na narrativa de todas as famílias a deficiência no funcionamento do mecanismo de referência e contrarreferência no atendimento à criança, sendo que a maioria dos serviços não contempla o apoio em relação aos cuidados, à assistência profissional e atenção à família como um todo. Para suprir essa lacuna, as familias buscam a assistência privada para a criança, alegando perceber melhores condições de atendimento, agilidade e segurança.

Tudo é melhor [na assistência privada]! Até mesmo no jeito de tratar a criança e o tempo de espera na fila. Porque, pensa bem, vocêsair de casa de madrugada com uma criança com $14 \mathrm{Kg}$, especial, que você tem que ter cuidados e ficar numa fila atéo meio dia para ter consulta não tem cabimento. (A3)

A experiência vivenciada por essas familias com os profissionais do serviço público de assistênciaà saúde foi ruim, pois não encontraram facilidades diante da condição da criança e nem perceberam manifestação de interesse deles em relação à criança.

Uma vez que ele ficou doente, antes detero plano [convênio particular], eu levei ele no hospital. O médico olhou para minha cara efalou "Seria bom se você tivesse um plano de saúde, porque esse tipo de criança eu não aconselho você trazer aqui". Eufalei 'Então vocêfecha o hospital'. (A3)

Na literatura ${ }^{11}$ descobrimos que as famílias criam uma expectativa antes de conhecerem os profissionais da saúde e ao se depararem com aqueles que não as acolhem, não as auxiliam nos cuidados espeć́ficos da criança e não escutam seus anseios e necessidades, sentem-se desamparadas.

\section{Apoio familiar}

Ao atravessar dificuldades a familia extensa se une e fortalece seus vínculos, o que é percebido desde a ocasião do diagnóstico, bem como no auxilio ao cuidado, aceitação e carinho pela criança, priorizando seu bem-estar e enfrentamento das adversidades. Em muitos casos, a criança torna-se centro de todas as atenções, como se a existência dela fortalecesse os laços. A aceitação da criança como ela é passa a ser um ponto fundamental para a família, que a defende e a protege.

Ele veio para ajudar a familia a aprender alguma coisa. A minha familia era cada um por sie Deus por todos. Eu via a minha mãe uma vez por ano sendo que minha mãe mora na mesma cidade. Minha irmã eu passei três anos sem vê-la, sendo que ela mora a três quarteirões daqui. Hoje não! Se tem uma data que dá para juntar todo mundo nós nos reunimos. (A3)

Contudo, nem todas as famílias vivenciam o apoio em suas relações. A rejeição é evidenciada quando os membros negam a condição da criança e não auxiliam nas atividades de vida diária, por acreditarem que existem peculiaridades que eles não dominam ou julgam que cuidar não é o seu papel. Isso provoca no cuidador principal tristeza, pois sente falta de apoio, fazendo-o refletir sobre como seria bom se alguns membros distantes estivessem por perto.

A familia por parte do pai nem quer saber que o menino existe. Eles vêm ver uma vez por ano e olhe lá! (A3)

Possivelmente a anormalidade estreita os laços familiares pelo fato de os pais conceberem na diferença da criança uma oportunidade para potencializar a comunicação $0^{12} .0$ auxilio e 0 apoio dos demais familiares no cuidado da criança são de suma importância para enfrentar a situação ${ }^{7}$.

\section{Apoio religioso}

A família encontra na religião amparo para a trajetória, bem como respostas para os questionamentos sobre o motivo da vinda dessa criança. Essas respostas abarcam diversos modos de significar a condição imposta à família, desde um aspecto positivo, ou seja, a missão de ensinar o próximo ou a possibilidade de estabelecer relação com pessoas que vão auxiliar na trajetória, até uma conotação negativa ao considerar o aspecto justiceiro.

Seique eles [os filhos] chegaram à minha existência por Deus e fico seguro de que, se um dia for chamado de retorno à vida espiritual antes deles, Deus haverá de fazê-los chegar a quem os ame como eu os amo! (P4)

A família se pauta na religião para atribuir significados à sua vivência e para se sentir acolhida nos momentos de sofrimento. Os familiares creem que Deus, mesmo não atendendo a todas as suas preces, tem o poder de curar a criança e livrá-la de complicações, fortalecendo a familia para continuar a luta ${ }^{13}$.

\section{Apoio financeiro}

A família enfrenta momentos difíceis relacionados à falta de recursos financeiros, já que os custos envolvidos no cuidado à criança são altos, geralmente incompatíveis com a renda mensal. Recebe apoio de parentes, amigos e solidariedade da comunidade para adquirir produtos e medicamentos. Tal ajuda não é constante, e quando a família não a recebe, tem que despender recursos próprios. A rede pública fornece apoio seja por auxilio financeiro ou recurso material, o qual abarca transporte, alimentação e vestimentas.

Eu recebo três pacotes de fralda da Assistente Social. É pouco, mas já ajuda. (M2) 
Ela recebe um benefício do governo. (M2)

Se tem um brinquedo, uma novidade que tenha luz, som, eles dão um jeito de trazer. Eles [os tios] não compram para os filhos deles, mais compram para ele. (A3)

Certos autores ${ }^{14}$ pontuam algumas ações governamentais e não governamentais no apoio à criança com anomalia congênita, dentre elas o Programa de Doença de Gaucher, Programa de Osteogênese Imperfeita, ECLAMC (Estudo Colaborativo Latino-Americano de Malformações Congênitas),SIATs (Sistema de Informações sobreAgentes Teratogênicos), SIEM (Serviço de Informação sobre Erros Inatos do Metabolismo), PNTN (Programa Nacional de Triagem Neonatal), além dos programas de prevenção. No presente estudo foi constatado que algumas familias são assistidas por benefícios públicos, o que deveria ser aplicado a todas, uma vez que as condições especiais das crianças, como imobilidade, deficiência visual, auditiva e cognitiva causam gastos com materiais espećíicos, como sondas, aparelho auditivo, cadeira de rodas, além da necessidade de assistência médica rotineira, que os familiares não têm condição de arcar.

\section{Mundo que envolve o cuidado}

A familia assume os cuidados da criança integralmente. Porém, é na figura do cuidador que esse amparo está centrado. Sua rotina contempla os horários de cuidados e consultas médicas. Com isso, a dedicação exclusiva à familia, e mais especificamente à criança, acaba anulando as possibilidades de o cuidador de realizar outras atividades, tanto pelo cansaço quanto pela falta de tempo.

Apesar de as demandas diárias serem desgastantes e o cuidado estar centralizado nafigura de uma pessoa, osignificado que lheéatribuido tambémé concebido como gratificante.

\section{Sentimentos relativos ao cuidado}

Ao contar sua história sobre a experiência de vivenciar a doença, a familia demonstra querer que a criançafaça sentido em suas vidas eque, de alguma maneira, influencie ofuturo 5 .

Assim a familia acredita ser inexplicável a sensação de cuidar de uma criança comnecessidades especiais eatribuiimensa alegriae satisfação aessarelação. 0 cuidador sesente privilegiado, pois acredita quetambémé especial e que está em constante aprendizado com a criança. Independentemente da anomalia, amae cuida da melhor maneira possível. Além disso, acredita que seu papel não se restringe apenas diretamente ao cuidado prestado, mastambémàs lições devida que devem ser atentamente observadas e aprendidas. Evidencia-se nas narrativas a importância das interações estabelecidas, pois por meio delas os laços se fortalecem eno processo de cuidar háo encantamento pela criança emenor percepção da anomalia.

Quanto às dificuldades sentidas pela familia, essas se devem principalmente ao cuidado centralizado nafigura de uma pessoa, a qualé responsável por atender a criança em todas as suas necessidades, o que podetornar a rotina exaustiva. Porém, mesmo diante das dificuldades, elase dedica eacreditaque todos essesfatores são compensados pelo bem-estar efelicidade da criança, esente-se culpada quando experiencia sentimentos de cansaço e falta de paciência.
Éuma emoção viver com ele [...]. Égratificante, porque eu vejo nele o que eu posso fazer. (A3)

Todo dia é uma luta. [...]. Eu diria então que cuidar bem é viver perigosamente. Dor está no nome e deveria ser sobrenome de todo cuidador. Dor nas costas, nos braços, no pescoço, na alma, no coração, na consciência. Dói tudo, mas só reclama quem quer! (P6)

Em um primeiro momento a família sente-se no dever de cuidar da criança, como sendo sua obrigação atender a suas necessidades. Porém, à medida que o tempo passa os vínculos entre a familia e a criança se estreitam de maneira tão forte e positiva que o cuidar não é mais encarado como obrigação, e sim como forma de demonstração de amor. A família classifica esse amor como incondicional e não mede esforços para cuidar da criança da melhor maneira possivel ${ }^{15}$. 0 cuidar atrelado ao amar desperta e traz a sensação de prazer e felicidade nas familias que se sentem completas com a criança.

A cumplicidade entre mãe e filho faz com que a primeira, nos momentos de sofrimento, refita sobre tudo o que aprendeu ao longo do tempo com as dificuldades e acredita que levará esse aprendizado para todaavidaeseengrandece, pois se caracterizacomo serhumano especial' .

Eume sinto umapessoamuito privilegiada deter a G. comigo [...] a criançaéespecial, mas os paistambém. (M2)

[...] devemos aceitá-los como são, pois eles têm muito para nosensinar,mesmoparecendo quesomossónósquedamos e cuidamos. O dia a dia, otempo, vaimostrando isso. Tenho certezaquelánafrentevamos olharparatrásevertudoque agentepassou, tudo que aprendemos, quãoútilfomos nessa vida equanto amor existiunela. (M6)

\section{Superproteção}

Afamilia sente-se insegura em deixar a criança realizar algumas atividades sozinha, pois a concebe como frágil e a vê necessitando de cuidados especiais, supervisão diretae eininterrupta. Apreocupação central coma criança no período pré-escolar (de 0 a 6 anos) diz respeito ao receio quandosealimentasozinha, poisháomedo de possíveisengasgos. Acreditar que a criançaé mais passível de infecções também provoca insegurança relacionadaàhigiene.

Eunão deixo irláfora, porque eutenhomedo que ela coloque alguma coisana boca. Então limpo bastante o chão, esóna hora que estábem limpoeucoloco elaparabrincar. Também tenho medo que ela engasgue, bala eu nem dou para ela. Bolachaeumaceroe dounaboca. Ela precisa de cuidados especiais, e são esses que eu e meu esposo damos a ela. (M5)

A mãe sente-se bem em cercar todas as possibilidades de falhas no cuidado, pois isso a tranquiliza e faz com que acredite que está fazendo o melhor. Essas atitudes são caracterizadas como uma 
barreira utilizada pela mãe e que, ao mesmo tempo, servem para seu próprio cuidado e proteção ${ }^{17}$.

\section{Momentos de lazer}

Para amenizar os fatores estressores, a família busca atividades de lazer e diversão para a criança. Com isso, o vínculo acaba sendo reforçado e a criança sente-se feliz por aproveitar outros espaços e estar cercada por seus familiares em um momento prazeroso. Nessas ocasiões, as interações são mais descontraídas e fluem em clima de alegria.

Meu lazer ébrincar com a G. Vou láe sento com ela, canto as musiquinhas ebrinco. Parece que eu volteia ser criança! (M2)

A familia, ao se ver envolvida com atividades de lazer, acredita que está contribuindo para melhor inclusão e desenvolvimento da criança e também melhorando o casamento e a comunicação no ambiente familiar ${ }^{18}$. Entretanto, apesar dos benefícios para a família e para a criança, essa prática acaba ficando em segundo plano diante das tantas obrigações do dia dia.

\section{CONSIDERAÇÕES FINAIS}

0 presente estudo teve por finalidade compreender a experiência da família no cuidado da criança portadora de anomalia congênita. Trata-se de uma vivência vasta e rica, permeada de momentos de dor, mas também de muita força e enfrentamento.

A limitação da pesquisa se relaciona à delimitação da faixa etária (pré-escolar), oque não possibilittou comparações entre as experiências ao longo dosanos. Ademais, aponta-se anecessidade de realizar maiornúmero de encontros com essasfamilias, pois por meio do fortalecimento do vínculo poderiam surgirnovas demandas que, possivelmente, ajudariamainda mais os profissionais de saúde a conhecerem as suas necessidades.

Percebeu-se que o Interacionismo Simbólico permeou toda a experiência e colaborou para a compreensão das narrativas, uma vez que a interação da família (o núcleo familiar, tanto na relação mais extensa quanto na mais distante) com a criança, com a anormalidade e com a sociedade, com os profissionais de saúde, com as redes de apoio gerou significados que foram expostos pelos familiares.

Com a análise dos resultados, pode-se evidenciar a necessidade de os profissionais da saúde atuarem como um real apoio a essas famílias, mais do que orientando a realização do cuidado, como a escuta qualificada, também investindo nas relações interpessoais, para efetivamente qualificar a assistência e auxiliar a família da criança com anomalia.

\section{REFERÊNCIAS}

1 Guiller CA; Dupas G; Pettengill MAM. Criança com anomalia congênita: estudo bibliográfico de publicações na área de enfermagem pediátrica. Acta paul. enferm. 2007jan/mar; 20(1): 18-23.

2 Roecker S; Mai LD; Baggio SC; Mazolla JC; Marcon SS. Vivência de mães de bebês com malformação. Esc. Anna Nery Rev. Enferm. 2012 jan/mar, 16(1): 17-26.
3 Santos R da S, Dias IMV. Refletindo sobre a malformação congênita. REBEN. 2005; 58(5): 592-6.

4Blumer, H. Symbolic interactionism: perspective and method. Berkeley: University of California Press; 1998. (trabalho original publicado em 1969)

5 Silva DGV, Trentini M. Narrativas como técnica de pesquisa em enfermagem. Rev. Latino-Am. Enfermagem. 2002 maio/jun.; 34(10): 423-32.

6 Guiller CA; Dupas G; Pettengill MAM. 0 sofrimento amenizado com o tempo: a experiência da família no cuidado da criança com anomalia congênita. Rev. LatinoAm. Enfermagem. 2009 jul./ago.; 17: 495-500.

7 Pizzignacco TP; Mello DF; Lima RG. A experiência da doença na fibrose cística: caminhos para o cuidado integral. Rev. Esc. Enferm. USP. 2011; 45(3): 638-44.

8 Lopes FN; Fialho FA; Dias IMAV; Almeida MB de; Nascimento L do. A vivência materna diante do defeito congênito: contribuiç̧ões para a prática da enfermagem. HU rev. 2011 jan./mar.; 37(1): 47-54.

9 Martins Aj; Cardoso MHC de A; Junior JCL. Em contato com as doenças genéticas: a norma e a razão como tradições culturais presentes no discurso de profissionais médicos do Instituto Fernandes Figueira, Fundação Oswaldo Cruz, Rio de Janeiro. Cad. saúde pública. 2004 jul./ago.; 20(4): 968-75.

10 Pinto JP; Ribeiro RC; Silva CV. Procurando manter o equilibrio para atender suas demandas e cuidar da criança hospitalizada: a experiência da famillia. Rev. LatinoAm. Enfermagem. 2005 nov./dez.; 13(6): 974-81.

11 Silveira AO; Angelo M. Interaction experience for families who lives their child's disease and hospitalization. Rev. Latino-Am. Enfermagem. 2006 nov./dec.; 14(6): 893-900.

12 Murray CE, Kelley-Solderhol EL, Murray TL. Strengths, challenges, and relational processes in families of children with congenital upper limb differences. Fam. syst. health. 2007 sep.;25(3):276-92.

13 PaulaES de; Nascimento LC; RochaSMM. Religião eespiritualidade: experiência de familias de crianças com Insuficiência renal crônica. REBEN. 2009; 62(1): 100-6.

14 Horovitz DDG; Cardoso MHA de A; Junior JCL; Mattos RA de. Atenção aos defeitos congenitosnoBrasil,panoramaatual. Cad. saúde pública. 2005jul./ago,;21(4): 1055-64.

15 Andrade MB de; Dupas G; Wernet M. Convivendo com a criança com hidrocefalia: experiência da familia. Ciênc. cuid. saúde. 2009; 8: 436-43.

16 Almeida MI, Molina RCM, Vieira TMM, Higarashi IH, Marcon SS. 0 ser mãe de criança com doença crônica: realizando cuidados complexos. Esc. Anna Nery Rev. Enferm. 2006 abr:; 10(1): 36-46.

17RibeiroC; MadeiraAMF.0 significado de sermãe de umfilho portador de cardiopatia: um estudo fenomenológico. Rev. Esc. Enferm. USP. 2006 mar:; 40(1): 42-9.

18 Marchese DM de A. Descarte de recém-nascidos com deformidades: relendo fontesprimárias. Estud. psicol. (Campinas). 2002 set./dez.; 19(3): 23-9.

\section{NOTA}

aParte dos resultados do Projeto de Iniciação Científica vinculado à FAPESP desenvolvido no período de janeiro 2011 a janeiro de 2012. 